failure become more common. ${ }^{3}$ It is particularly remarkable that our patient, despite her advanced age and large shunt, had no symptoms of angina pectoris. This is likely thanks to the significant osteal stenosis of the CS, which would have maintained a relatively high intracoronary sinus pressure, minimizing the steal phenomenon from the right coronary system. Although the intracoronary sinus pressure was not measured directly, the degree of aneurysmal dilatation of the CS is indirect evidence of the same.

The cause of this patient's coronary abnormalities is uncertain, although one might presume the fistula to be congenital in origin, with the aneurysm being caused by altered flow dynamics in the RCA. The most common cause of aneurysm of the coronary artery is atherosclerosis; however, the patient had no other atherosclerotic burden in her coronary system. Other possible causes are Kawasaki disease, Takayasu arteritis, systemic lupus erythematosus, polyarteritis nodosa, bacterial infection, septic embolism, and trauma. There was no evidence of these causes in our patient, however.

\section{References}

1. Li D, Wu Q, Sun L, Song Y, Wang W, Pan S, et al. Surgical treatment of giant coronary artery aneurysm. J Thorac Cardiovasc Surg. 2005;130:817-21.

2. Matawari T, Koshino T, Morishita K, Komatsu K, Abe T. Successful surgical treatment of giant coronary artery aneurysm with fistula. Ann Thorac Surg. 2000;70:1394-7.

3. Cheung DL, Au WK, Cheung HH, Chiu CS, Lee WT. Coronary artery fistulas: long-term results of surgical correction. Ann Thorac Surg. 2001;71:190-5.

4. Schmid FX, Elsner D, Merk J, Birnbaum DE. Giant right coronary artery-coronary sinus fistula. Eur J Cardiothorac Surg. 2002;21:929.

5. Firstenberg MS, Azoury F, Lytle BW, Thomas JD. Interposition vein graft for giant coronary aneurysm repair. Ann Thorac Surg. 2000;70:1397-8.

\title{
Rapid extracorporeal life support rescue in patients undergoing the Norwood procedure
}

\author{
Nathalie Roy, MD, ${ }^{\mathrm{a}}$ Ivan M. Rebeyka, MD, ${ }^{\mathrm{a}}$ Joseph Atallah, MD, ${ }^{\mathrm{b}}$ and David B. Ross, MD, ${ }^{\mathrm{a}}$ Edmonton, Alberta, Canada
}

Neonates undergoing the Norwood stage I procedure are susceptible to postoperative hemodynamic instability, low cardiac output, and sudden cardiac arrest. The outcome of rescue extracorporeal life support (ECLS) after the stage I procedure is likely improved when deployment can be achieved in an efficient manner. We describe a simple and rapid technique of arterial cannulation for rescue ECLS using a $3 \mathrm{~mm}$ polytetrafluoroethylene (PTFE) graft based on a technique of selective intraoperative arterial perfusion during the aortic arch reconstruction.

\section{CLINICAL SUMMARY}

The perfusion strategy for the Norwood stage I procedure with a right ventricle-pulmonary artery (RV-PA) shunt ${ }^{1}$ uses an $8 \mathrm{~F}$ arterial cannula (Medtronic, Minneapolis, Minn) inserted within a $3 \mathrm{~mm}$ PTFE graft (W.L. Gore and Associates, Newark, Del) anastomosed to the innominate artery. ${ }^{2}$ A period of low-flow cerebral perfusion at $50 \mathrm{~mL} \cdot \mathrm{kg}^{-1} \cdot \mathrm{min}^{-1}$

\footnotetext{
From the Divisions of Cardiac Surgery, ${ }^{\mathrm{a}}$ and Pediatric Cardiology, ${ }^{\mathrm{b}}$ Stollery Children's Hospital and University of Alberta, Edmonton, Alberta, Canada. Received for publication Nov 21, 2007; accepted for publication Dec 24, 2007. Address for reprints: Nathalie Roy, MD, 2D4.37 Walter C. MacKenzie Centre 8440112 St, Edmonton, Alberta, Canada, T6G 2B7 (E-mail: nroy1@ualberta.ca). J Thorac Cardiovasc Surg 2009;137:765-6 $0022-5223 / \$ 36.00$ Copyright (c) 2009 by The American Association for Thoracic Surgery doi:10.1016/j.jtcvs.2007.12.071
}

is used during the aortic arch repair, followed by a short period of circulatory arrest for the atrial septectomy and at times for the proximal aortic reconstruction. At the end of the procedure, the PFTE graft is occluded at its base with the innominate artery by using a vascular clip and trimmed to a length of $4 \mathrm{~cm}$ (Figure 1). The sternum is stented open with primary skin closure. ${ }^{3}$ If the postoperative period is uneventful, the graft is shortened to a few millimeters at the time of chest closure. In the event Emergency ECLS is required in the postoperative period, the graft is irrigated with a saline solution, the clips are removed, and the arterial cannula is inserted into the graft for systemic perfusion. The cannula is deaired in a retrograde fashion before connecting it to the ECLS circuit.

A 1.6-kg male infant born at 32 weeks of gestation was diagnosis with hypoplastic left heart syndrome with mitral and aortic atresia. He underwent a Norwood stage I procedure with a $5 \mathrm{~mm}$ RV-PA shunt at 6 weeks of life and a weight of $2.5 \mathrm{~kg}$.

The baby had a stable early postoperative period but experienced a cardiac arrest caused by tamponade from a displaced intracardiac line. Rapid arterial cannulation for ECLS was obtained by inserting an $8 \mathrm{~F}$ cannula into the stump of the aforementioned graft used for selective perfusion during the stage I procedure. Venous cannulation was performed through a purse-string suture in the right atrial 


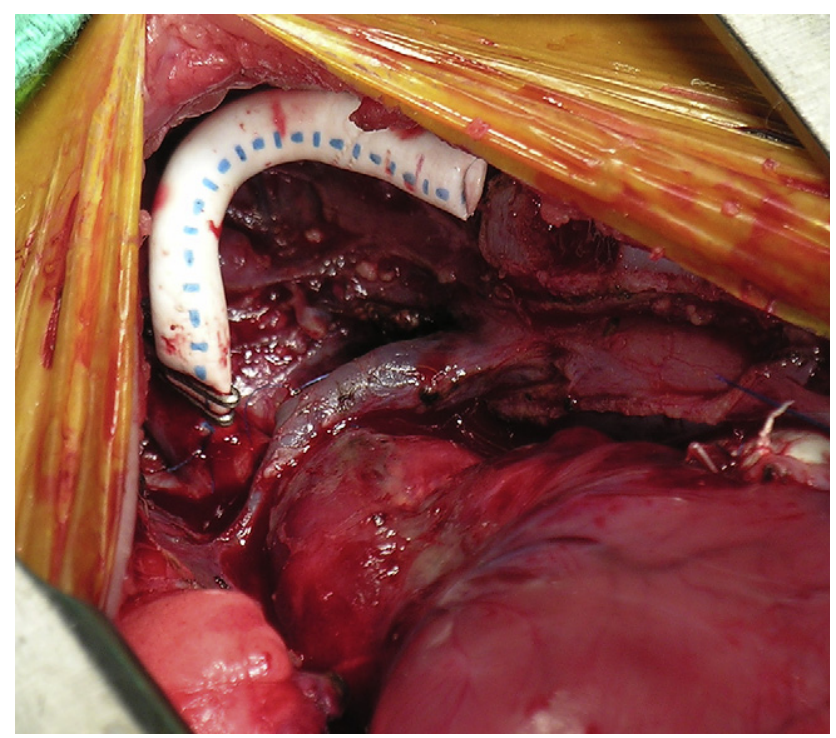

FIGURE 1. A $3.0 \mathrm{~mm}$ PTFE graft is used for selective aortic perfusion during the aortic arch reconstruction while performing a Norwood stage I procedure with RV-PA shunt. The shunt is clipped at the base of the innominate artery after the procedure and can be used for rapid deployment of ECLS in the early postoperative period.

appendage. The baby was supported for 8 days and was successfully weaned off ECLS, extubated, and transferred to a regional hospital for convalescence.

From 2002-2005, 32 Norwood stage I procedures with RV-PA shunts were performed at our institution. Early postoperative and 2-year mortality were $6 \%(2 / 32)$ and $19 \%$ (6/32), respectively. Two patients required cardiopulmonary resuscitation postoperatively, and $1(3 \%)$ required ECLS.

\section{DISCUSSION}

This perfusion strategy for the modified Norwood stage I procedure allows the surgeon to perform the aortic arch repair by using low-flow cerebral perfusion with a brief period of circulatory arrest. It minimizes trauma to the innominate artery and prevents inadvertent decannulation by keeping the cannula out of the surgical field.

Leaving a short remnant of PTFE graft beyond the clips at the end of the procedure offers an easy cannulation site for rescue ECLS. It provides safe and rapid access for arterial perfusion and minimizes bleeding associated with cannulation of the reconstructed aorta.

Successful resuscitation of a neonate from cardiac arrest after the Norwood stage I procedure with ECLS requires rapid cannulation that can be achieved by using the described technique.

\section{References}

1. Sano S, Ishino K, Kawada M, Arai S, Kasahara S, Asai T, et al. Right ventriclepulmonary artery shunt in first-stage palliation of hypoplastic left heart syndrome. J Thorac Cardiovasc Surg. 2003;126:504-10.

2. Vricella LA, Samankatiwat P, de Leval MR, Tsang VT, Vouhe PR. Simplified antegrade cerebral perfusion and myocardial protection during stage I Norwood procedure. Asian Cardiovasc Thorac Ann. 2004;12:372-3.

3. Al-Sehly AA, Robinson JL, Lee BE, Taylor G, Ross DB, Robertson M, et al. Pediatric poststernotomy mediastinitis. Ann Thorac Surg. 2005;80:2314-20.

\section{Treatment of anastomotic leaks after esophagectomy with endoscopic hemoclips}

Celal Tekinbas, MD, ${ }^{\mathrm{a}}$ M. Muharrem Erol, MD, ${ }^{\mathrm{a}}$ Remzi Akdogan, MD, ${ }^{\mathrm{b}}$ Serdar Turkyilmaz, MD,${ }^{\mathrm{c}}$ and Mehmet Aslan, MD,

Trabzon, Turkey

Mortality and morbidity levels following esophageal resection are high. ${ }^{1}$ Anastomotic leaks are a major cause of this morbidity and mortality. ${ }^{2}$ Early and appropriate treat-

From the Departments of Medicine, ${ }^{\mathrm{a}}$ Internal Medicine, ${ }^{\mathrm{b}}$ and General Surgery, ${ }^{\mathrm{c}}$ Karadeniz Technical University, Trabzon, Turkey.

Received for publication Dec 1, 2007; accepted for publication Jan 20, 2008.

Address for reprints: Celal Tekinbas, MD, Karadeniz Teknik Üniversitesi, Tıp Fakültesi,

Göğüs Cerrahisi AD, 61080 Trabzon, Turkey (E-mail: celaltekinbas3@hotmail.com).

J Thorac Cardiovasc Surg 2009;137:766-7

$0022-5223 / \$ 36.00$

Copyright (C) 2009 by The American Association for Thoracic Surgery

doi:10.1016/j.jtcvs.2008.01.052 ment is essential. Various methods and techniques are employed for fistula closure, including aggressive surgery, esophageal T-tube drainage, esophageal stent, and conservative management. Yet there is still much controversy on the best form of treatment. ${ }^{1-3}$ Esophageal clips are increasingly being used for the treatment of benign esophageal diseases such as perforations. These are easy to insert and remove, and good outcomes have been reported. ${ }^{4}$ To the best of our knowledge, there are no previous reports concerning the use of endoscopic clips in the closing of esophageal anastomotic fistulae. We describe a case of early postoperative 